\title{
Improved Quantitative PCR Using Nested Primers
}

\author{
Lawrence A. Haff \\ Applied Biosystems Division, The Perkin-Elmer Corporation, Norwalk, Connecticut 06859
}

\begin{abstract}
Quantitative PCR can often be improved by conducting the amplification with nested primers. First, fewer nonspecific amplification products, which could otherwise interfere with quantitation, are produced. Often, nonspecific products can be eliminated. In these cases, relatively simple nonspecific detection techniques are suitable for quantitation. In addition, nested primer PCR provides intrinsic PCR product carryover protection and generally improves the robustness and lower limit of detection of PCR. For a nested PCR to provide useful quantitative information, it is important that the initial phase of amplification, performed with the outer pair of primers, takes place entirely in the exponential phase. This is generally achieved easily. The major consideration in designing a nested PCR protocol compatible with quantitation is to assure that the maximum concentration of PCR products produced by the outer primers does not exceed $\sim 10 \%$ the molarity of the outer primers. A simple formula can be used to determine the maximum number of thermal cycles that provide this assurance. Good correspondence was obtained between initial target concentration and final PCR product yield in a nested-primer HIV-1 PCR.
\end{abstract}

$\mathbf{H}$ iguchi et al. ${ }^{(1)}$ described a powerful and convenient method to detect and quantify PCR amplification products by fluorescence enhancement in ethidium bromide. These data can be treated in at least two ways to estimate the initial concentration of a target sequence. First, from data taken in the exponential amplification phase, the step cycle efficiency can be calculated and original target concentration easily calculated. ${ }^{(2)}$ Higuchi et al. ${ }^{(1)}$ also demonstrated that the initial target sequence concentration could be calculated from data obtained in the nonexponential phase (or plateau phase), based on the calculated number of PCR cycles required for PCR product to reach an arbitrarily selected threshold concentration. A major technical advantage of this approach is that comparatively simple and inexpensive instrumentation can often provide adequate sensitivity to detect amplification products in the nonexponential phase (typically, $10^{-8}$ to $10^{-7} \mathrm{M}$ PCR product). A major advantage of the use of such nonspecific detection techniques is the complete elimination of the requirement for labeled DNA probes.

However, a substantial objection to the wide implementation of intercalating dye detection is its lack of specificity. Unless the PCR is very specific, nonspecific products are quantitated together with specific products, and a false estimation of initial copy number may be obtained. This is particularly a problem for amplifications starting with low copy numbers of targets. Higuchi et al. ${ }^{(1)}$ noted that they were unable to quantify $<100$ target molecules of HIV because of the production of nonspecific products after many thermal cycles. Such nonspecific products are almost always generated after 40 cycles of PCR with a single set of primers, even with hot starts.

A widely accepted and generally effective solution to PCR nonspecificity is nested primer PCR. ${ }^{(3)}$ Nested primer PCR involves an initial set of thermal cycles with a pair of primers spaced relatively far apart. Then, an additional primer or pair of primers, located between the outer primers, is added, followed by a second round of thermal cycling. The set of inner primers is added at a higher concentration than the outer primers. After a few thermal cycles, inner primer PCR product predominates.

Because the discriminatory power of nested primer PCR is so high, a single PCR product can often be obtained with low target concentrations. Although both the inner and outer primers will produce some, but different, nonspecific amplification products, these will often fail to reach detectable levels in a nested PCR. This is because, first, the concentration of outer primers is too low for the corresponding nonspecific amplification products to reach detectable levels. Second, although the inner primer PCR uses a higher primer concentration, the number of thermal cycles in this phase is generally limited so that these nonspecific amplification products also do not reach detectable levels.

Although nested primer PCRs are widely employed for detection, examples of applying nested primer PCR to quantitative applications are absent. This is probably because it is not necessarily intuitively obvious that a PCR conducted with nested primers would maintain a simple mathematical relationship between the amount of amplified product and the amount of target sequence. The major source of complexity is that the inner and outer primer PCRs are 
likely to have substantially different step cycle efficiencies. However, the results presented here indicate that a properly designed nested PCR will retain its utility for quantitation.

In this study a model nested PCR system was tested employing exponentialphase mathematical treatment. A nonspecific mode of detection was chosen, in which any PCR product, specific or nonspecific, containing both inner PCR primers would be included in the quantitation. Although electrochemiluminescent detection was employed, similar results should be expected with other nonspecific modes of detection, such as intercalating dyes.

\section{MATERIALS AND METHODS}

All reagents were obtained from the Applied Biosystems Division of PerkinElmer Corporation (Foster City, CA). An HIV-1 nested primer PCR model test system was prepared as described previously. ${ }^{(3)}$ The outer set of primers, SK380/ SK390, produce a 219-bp PCR amplification product, and the inner set of primers, SK38/SK39, produce a 115-bp amplification product (Fig. 1). Primer SK38 contained a 5'-biotin whereas primer SK39 contained a 5'-Tris(bypyridyl ruthenium) group. PCR products generated by the two inner primers can be captured on streptavidin-coated magnetic beads and quantitated by electrochemiluminescence (ECL). ${ }^{(4)}$

Each PCR contained $1 \times$ PCR II buffer (10 mM Tris- $\mathrm{HCl}$ at $\mathrm{pH} \mathrm{8.3,50} \mathrm{mM} \mathrm{potas-}$ sium chloride), $2.5 \mathrm{~mm}$ magnesium chloride, $0.2 \mathrm{~mm}$ each dNTP, 1.25 units of Amplitaq DNA polymerase, $0.1 \mu \mathrm{g}$ HIV1-negative human genomic DNA, and variable concentrations of outer and in- ner primers in a total volume of $100 \mu \mathrm{l}$. Variable amounts of HIV-1-positive control DNA (containing the complete HIV-1 genome, but rearranged for biological safety) were added.

Samples were thermal-cycled on a Perkin-Elmer DNA Thermal Cycler System 9600 as follows: outer primer PCR at initial denaturation of $95^{\circ} \mathrm{C}$; thermal cycle at $95^{\circ} \mathrm{C}$ for $15 \mathrm{sec}$ to $60^{\circ} \mathrm{C}$ for $120 \mathrm{sec}$, for 20 cycles; hold at $4^{\circ} \mathrm{C}$; add inner primers; cycle at $95^{\circ} \mathrm{C}$ for $15 \mathrm{sec}$ to $60^{\circ} \mathrm{C}$ for $120 \mathrm{sec}$, for 20 cycles; hold at $4^{\circ} \mathrm{C}$.

For electrochemiluminescent quantitation of total HIV-1 inner primer amplification product, $0.5-1 \mu \mathrm{l}$ of each sample was incubated with $30 \mu \mathrm{g}$ of streptavidin-coated magnetic beads at room temperature for $30 \mathrm{~min}$ in $50 \mu \mathrm{l}$ of $1 \times$ PCR II buffer containing $2 \mathrm{~mm}$ EDTA ( $\mathrm{pH} 8.3$ ). Seven hundred microliters of ECL assay buffer was added, and electrochemiluminescence was determined on the Q-PCR System 5000 (Perkin-Elmer Corporation). Standard curves relating electrochemiluminescence to PCR product concentration were prepared by quantitating amplified products by ethidium bromide assay $^{(5)}$ in a Perkin-Elmer LS-50 spectrofluorometer. Standard DNA concentration curves to calibrate the fluorescence measurements were prepared using purified $\lambda$ DNA (Life Technologies, Bethesda, MD). The concentration of these standards was determined by UV absorbance, assuming $20 A_{260} / \mathrm{mg}$ of DNA.

\section{RESULTS}

\section{Mathematical Model}

Figure 2 is a theoretical example of a nested PCR. It consists of 20 cycles of outer primer PCR followed by 20 cycles of inner primer PCR, each with different step cycle efficiency. Two different initial target concentrations, differing by a factor of 10 , were modeled (1,000 copies and 10,000 copies in a volume of $100 \mu \mathrm{l}$ ).

The model assumes conditions that are commonly observed in PCR. Generally, amplification remains in the exponential phase unless limited by enzyme concentration or by competition between primer and PCR product reannealing. PCR product reannealing generally becomes a factor only when the concentration of amplified PCR product approaches about one-tenth the original concentration of supplied primers. ${ }^{(1)}$ In the theoretical example in Figure 2, the amplifications just begin to leave a pure exponential mode of amplification and to enter the plateau phase at about onetenth the available inner primer concentration, or at $\sim 2 \times 10^{-9} \mathrm{M}$.

If the first, outer primer amplification is carried out with a step efficiency of $e_{1}$ for $n$ cycles and the second, inner primer PCR is carried out with a step efficiency of $e_{2}$ for $m$ cycles, then the yield of PCR product after the nested PCR, $S_{(m+n)}$ will be related to the starting target concentration, $S_{0}$, as follows, as long as both phases of the amplification remain in the exponential phase:

$S_{(m+n)}=S_{o} \times\left(1+e_{1}\right)^{n} \times\left(1+e_{2}\right)^{m}$

Comparing two PCRs with different starting target concentrations, it is clear that independent of the step cycle efficiency of this phase of amplification, as long as the outer primer PCR takes place entirely in the exponential phase, the ratios of PCR amplification products after the outer primer PCR will be same as the ratios before the amplification. After addition of the inner primers, almost all the amplification products will be the short, inner primer PCR product. The ratios of the inner PCR amplification products also reflect the starting ratios of target as long as the curves remain parallel.

In the example shown in Figure 2, after about cycle 33, the PCR of the target of the higher concentration of target DNA sequence gradually leaves the exponential phase. A nonexponential phase model $^{(1)}$ could be applied to data acquired after the exponential phase. Again, a nested PCR should not interfere with quantitation as long as the same

FIGURE 1 Model of HIV-1 nested PCR. The outer, unmodified primers SK380/SK390 produce a 219-bp PCR product. The inner primer SK38 contains a 5' biotin for capture of the 115-bp inner primer PCR product onto streptavidin-coated magnetic beads. The inner primer SK39 carries a $5^{\prime}$-Tris(bypyridyl)ruthenium group (TBR) for ELC detection. 


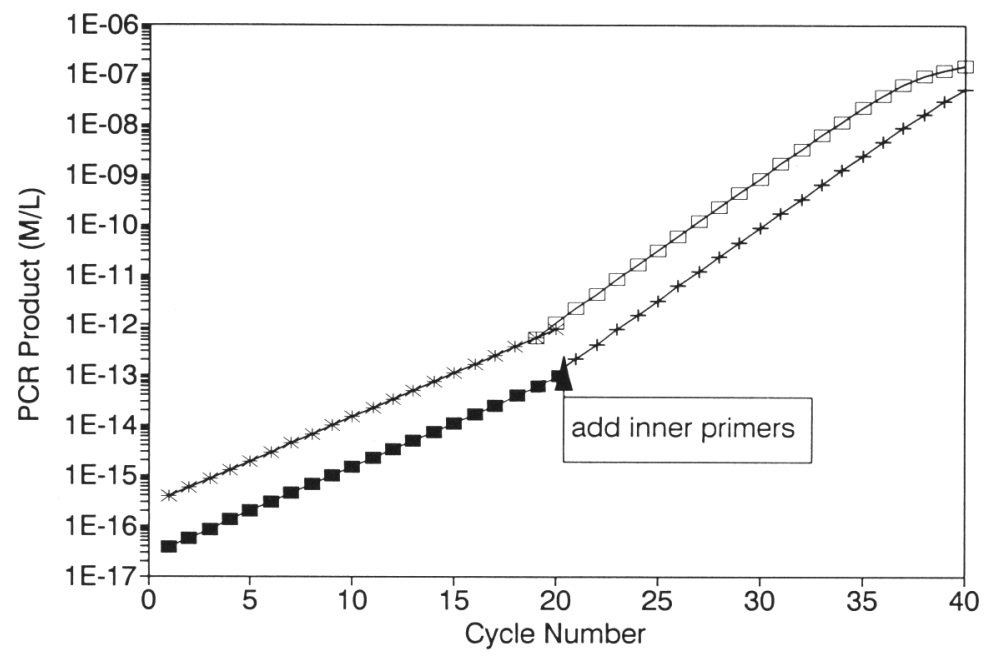

Start $=3.3 \mathrm{E}-17 \mathrm{M} / \mathrm{L}+$ Start $=3.3 \mathrm{E}-16 \mathrm{M} / \mathrm{L}$

FIGURE 2 Mathematical example of nested quantitative PCR. Two hypothetical PCRs containing either 1,000 or 10,000 target sequences $/ 100 \mu l$ were compared. It was assumed that outer primers were supplied at a concentration of $2 \times 10^{-8} \mathrm{M}$ and the outer primer PCR step cycle efficiency was 0.5 . At cycle $20,2 \times 10^{-8} \mathrm{M}$ of inner primers was added and the inner primer PCR conducted with step cycle efficiency of 0.95 . After reaching $\sim 1 / 10$ of the inner primer concentration, the amplification begins to depart from pure exponential amplification and approaches an asymptote of PCR product concentration equal to the original free primer concentration.

relative proportions of the amplification products were maintained throughout the first phase of amplification.

In this study the model HIV-1 nested primer PCR was tested against the theoretical model. For simplicity, the examination was limited to conditions in which the PCR remained in the exponential phase.

\section{Primer Concentrations Suitable for Quantitative Nested PCR}

In principle, for efficient nesting, the concentration of outer primers in the first phase of nested PCR should be kept as low as possible. The lower limit is subjected to two practical limitations. First, the outer primer concentration should not drop significantly during the outer primer PCR phase; if it did, the efficiency of this phase of the amplification might vary during the PCR. Clearly, if the outer primers were exhausted during the outer primer PCR, the linear correspondence between input copies and PCR product would be lost. Second, because primer annealing kinetics are concentration dependent, very low concentrations of outer primers might anneal too slowly to support amplification. Regaining ampli- fication efficiency would probably require a significant reoptimization of the PCR.

To determine the appropriate concentration range of outer primers for the model PCR, amplification yields were tested while varying the outer primer concentrations. The inner primer concentration was held constant at $2 \times 10^{-7} \mathrm{M}$.

As shown in Figure 3, the yield of inner primer-generated product in the nested PCR was relatively constant over a range of outer primer concentrations between $3 \times 10^{-8} \mathrm{M}$ and $2 \times 10^{-7} \mathrm{M}$. At higher concentrations of outer primers, the inner PCR product yield dropped because multiple hybrid PCR products of intermediate size were produced. This was evident by gel electrophoresis (data not shown). These multiple PCR products were probably the result of PCR occurring between combinations of inner and outer primers. It is also possible that some could have resulted from the inherent $3^{\prime} \rightarrow 5^{\prime}$ exonuclease activity of Taq DNA polymerase, the so-called TaqMan activity. ${ }^{(6)}$ However, this activity would normally be expected to produce an extremely heterogeneous mixture of degraded amplification products rather than a few discrete molecular sizes. Hybrid PCR products that contained either outer primer were not quantitated in the ECL assay because such products lack either the biotin capture group or ECL reporter group (Fig. 1).

At outer primer concentrations between $10^{-7}$ and $10^{-8} \mathrm{M}$, a single PCR product of $115 \mathrm{bp}$ was detected upon analysis by gel electrophoresis. However, yields were depressed, employing $<10^{-8}$ $\mathrm{M}$ outer primers, presumably as a result of slow annealing kinetics at this concentration. A 10-fold concentration range between $10^{-8}$ and $10^{-7} \mathrm{M}$ produced the best results under these experimental conditions.

These results suggest that the greatest latitude in appropriate concentrations for the outer primers would be obtained by selecting a relatively high concentration of inner primers, because the upper range of allowable outer primer concentration is limited to a proportion of the inner primer concentration.

\section{Quantitative Nested PCR}

Six nested PCRs were tested, which were identical except for differing initial target concentrations. Each contained, respectively, 0, 1,000, 2,500, 5,000, 10,000, and 25,000 copies of HIV-1-positive control target DNA in $100 \mu \mathrm{l}$. Each PCR was first amplified for 20 cycles with $2 \times 10^{-8}$ $M$ outer primers. After 20 thermal cycles, $5 \times 10^{-7} \mathrm{M}$ of inner primers were added, thermal cycling was continued, and aliquots were removed and quantitated by ECL. For comparison, parallel PCRs were run without nesting; these contained no outer primers but only $5 \times 10^{-7} \mathrm{M}$ of inner primers throughout the entire amplification.

As shown in Figure $4 \mathrm{~A}$, the nested PCR products were first detected at about cycle 35 . For most of the samples, the amplification appeared to remain in the exponential phase throughout cycle 45 . A linear correspondence between initial target molarity and final PCR product yield was maintained throughout the entire range, as shown in Figure 4B. (Because of the wide concentration ranges involved, these data were plotted on a $\log -\log$ scale. Of necessity, the data points for " 0 " molarity cannot be shown on a logarithmic plot.) A low concentration of ECL-detectable PCR products was detected in the 0 samples after thermal cycle 40 . As expected, these appear to be 


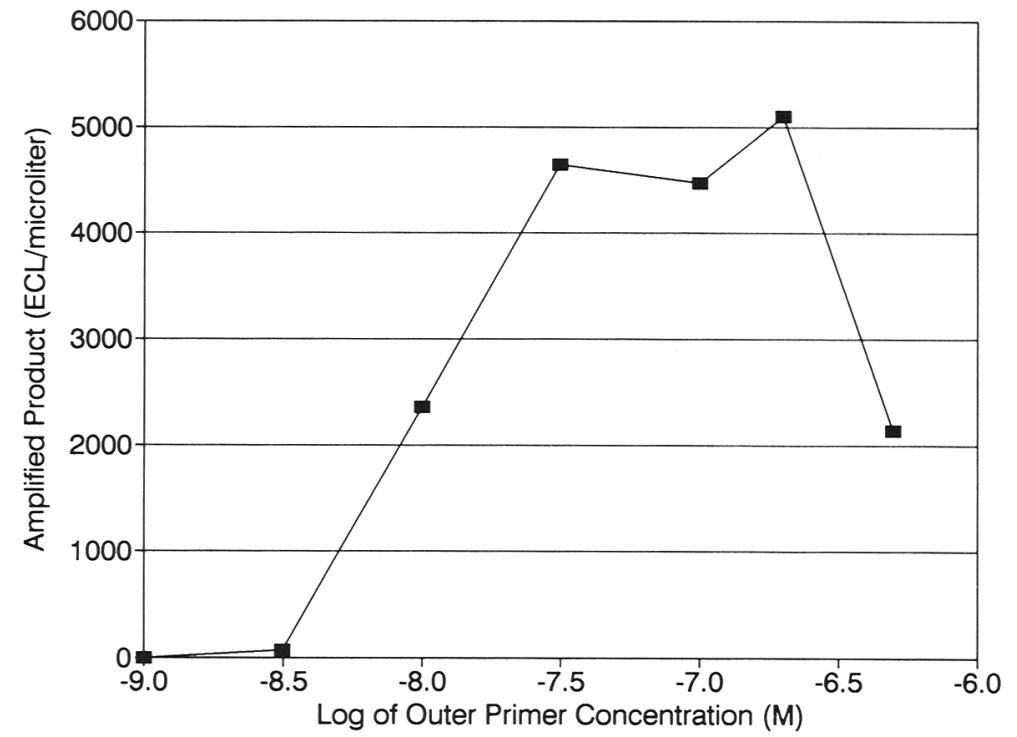

FIGURE 3 Variation of nested PCR yield with outer primer concentration. Nested PCR was carried out as described in Materials and Methods. Twenty cycles of outer primer PCR was carried out with variable concentrations of outer primers. Then, inner primers were added at a concentration of $5 \times 10^{-7} \mathrm{M}$, and the PCR was repeated for another 20 cycles. One microliter of each sample was subjected to ELC assay. In this assay, $1 \mathrm{ECL}$ unit $=7.83 \times 10^{-16} \mathrm{M}$.

nonspecific amplification products because they produced a background smear of amplification products upon electrophoresis rather than a distinct 115-bp band (data not shown).

Amplification products from the regular, un-nested PCR were detected in earlier cycles than the nested PCR (Fig. 5A). This indicates that the step cycle efficiency of the un-nested PCR must have been higher than the step cycle efficiency in the initial phase of the nested PCR. However, it appeared that much more nonspecific amplification product was produced in the un-nested PCR than in the nested PCR. In the un-nested PCR, a good relationship between input copies and amplified product was only obtained up to cycle 25 (Fig. 5B). With $>25$ thermal cycles, the background resulting from nonspecific products (i.e., produced with zero input copies) in the unnested PCR appeared to interfere with maintenance of good quantitation. Because the un-nested PCR had a higher average step cycle efficiency in the first 20 cycles than the nested PCR, it also left the exponential phase earlier.

\section{DISCUSSION}

The mathematical model [equation 1; Fig. 2] predicts that nested primer PCR is compatible with quantitation, requiring only that the initial, outer primer PCR take place completely in the exponential phase. This requirement proved fairly easy to accomplish during development of the model test system. The most robust conditions are a relatively high in-
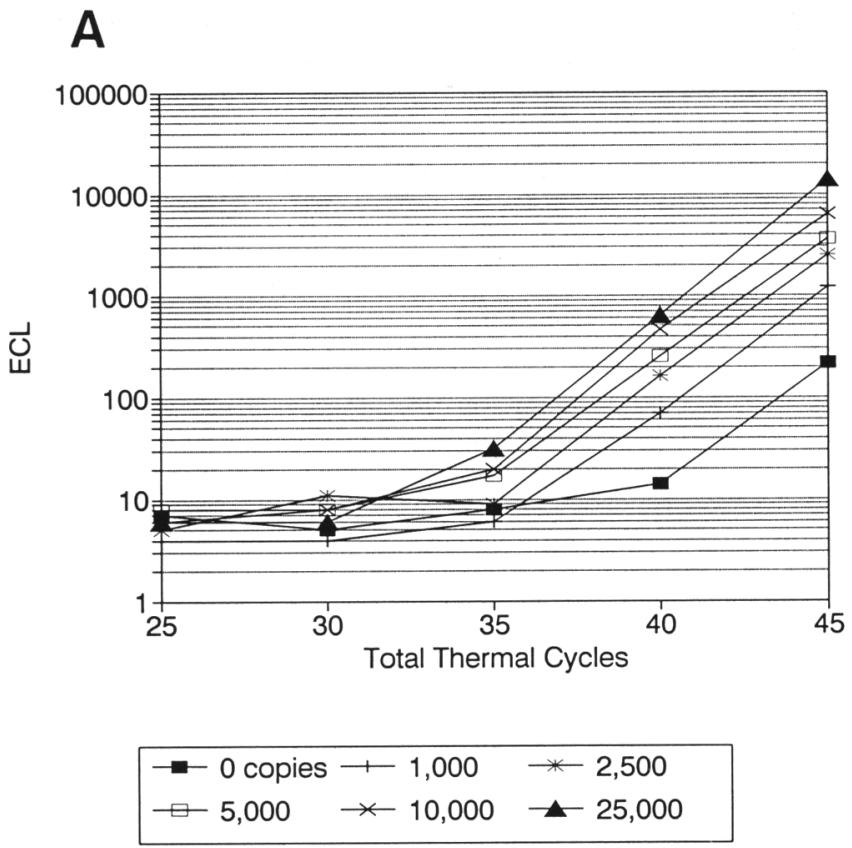

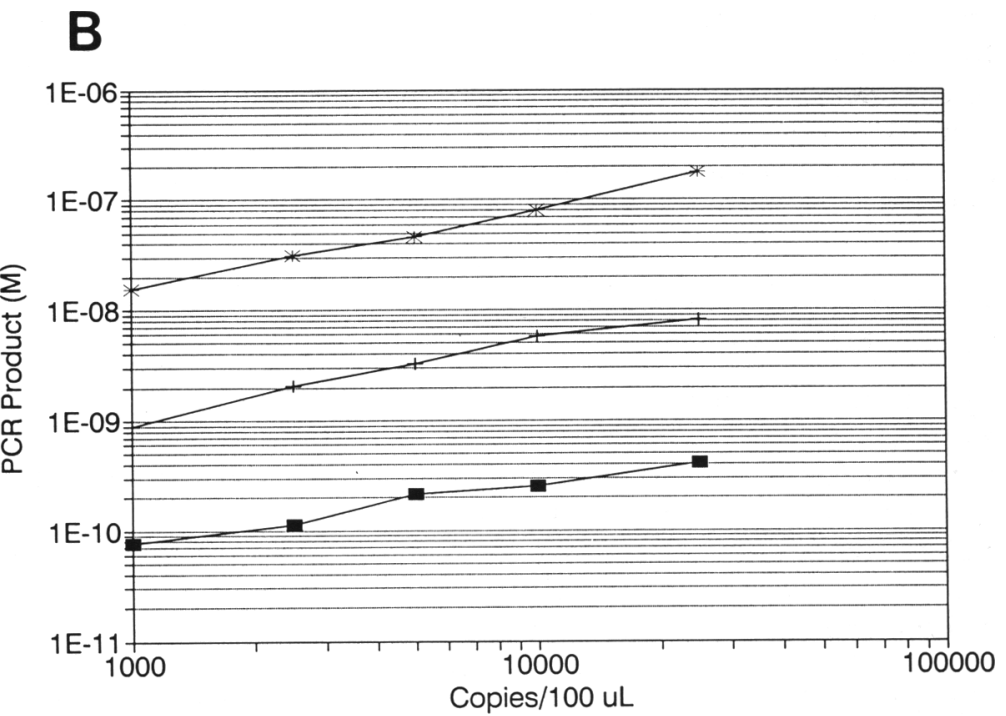

35 cycles +40 cycles $* 45$ cycles

FIGURE $4(A)$ Nested PCR yield vs. cycle number. Nested PCR was carried out as described in Materials and Methods with 20 cycles of $2 \times 10^{-8}$ outer primers. Then, $5 \times 10^{-7} \mathrm{M}$ inner primers were added, and aliquots were taken every five cycles for ELC measurement. Samples contained input levels of $0,1,000,2,500,5,000,10,000$, and 25,000 copies. In this assay, $1 \mathrm{ECL}$ unit $=7.83 \times 10^{-16}$ moles. $(B)$ Quantitative nested PCR; input copy number vs. PCR yield. PCR product yield was determined from the data in $A$, and the log input copies were plotted vs. the log of PCR product following amplification at 35,40 , or 45 cycles. Yields of PCR product from 0 input copies were $1.02 \times 10^{-10} \mathrm{M}$ at $35 \mathrm{cycles}, 1.79 \times 10^{-10} \mathrm{M}$ at $40 \mathrm{cycles}$, and $2.76 \times 10^{-9} \mathrm{M}$ at 45 cycles. 
A

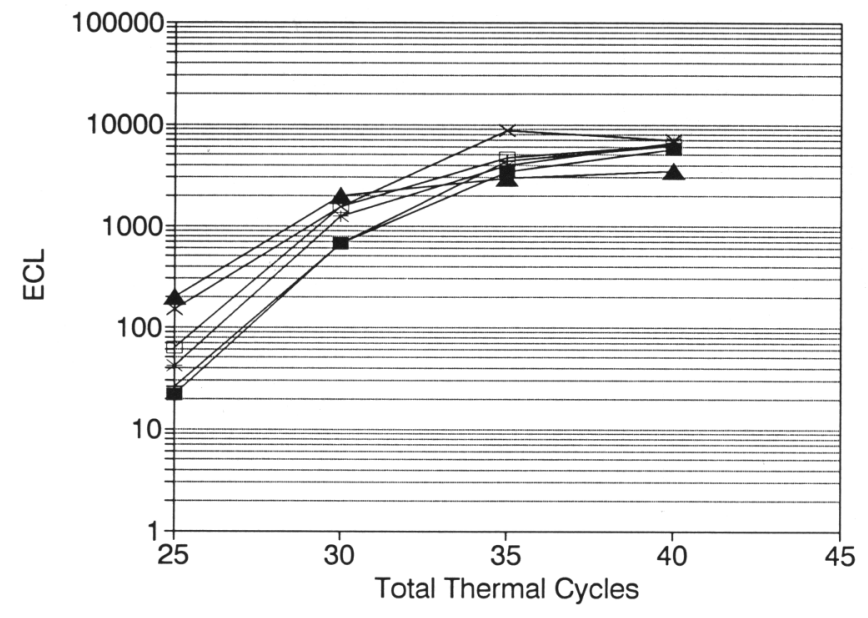

$$
\begin{aligned}
& -0 \text { copies } \leftarrow 1,000 \rightarrow 2,500 \\
& -5,000 \rightarrow 10,000 \leftarrow 25,000
\end{aligned}
$$

\section{B}

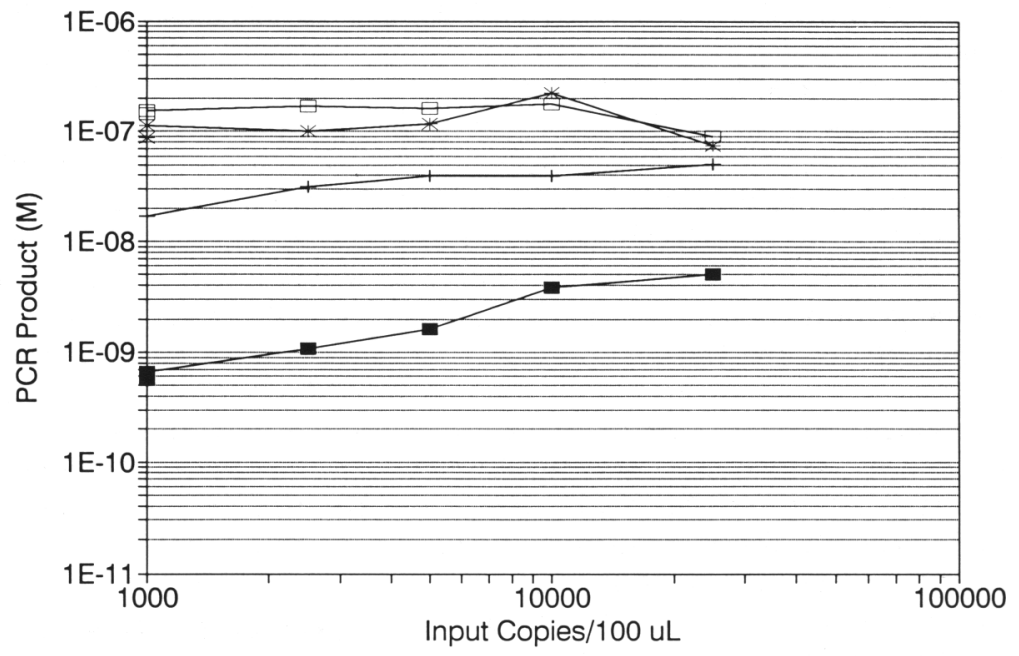

-25 cycles +30 cycles $* 35$ cycles $\square-40$ cycles

FIGURE $5(A)$ PCR with inner primers only; yield vs. cycle number. The PCRs were amplified as described for Fig. $4 \mathrm{~A}$, except that only $5 \times 10^{-7} \mathrm{M}$ inner primers were used throughout the amplification. $(B)$ Quantitative nested PCR with inner primer only; input copy number vs. PCR yield. PCR product yield was determined from the data in $A$, and the log input copies were plotted vs. the log of PCR product following amplification at 25 , 30,35 , and 40 cycles. The yields for 0 input copies were $5.62 \times 10^{-10} \mathrm{M}$ at 25 cycles, $1.78 \times 10^{-8} \mathrm{M}$ at 30 cycles, $8.79 \times 10^{-8} \mathrm{M}$ at 35 cycles, and $1.45 \times 10^{-7} \mathrm{M}$ at 40 cycles.

ner primer concentration $(0.5-2 \mu \mathrm{M})$ and about one-tenth this level for the outer primers. In the model PCR, concentrations of outer primers below about $10^{-8}$ $M$ reduced the amplification yield. The lowest suitable concentration is likely to vary with different PCRs and probably needs to be determined experimentally in each case.

The onset of nonspecific PCR product production was delayed in the model nested PCR compared with its un-nested counterpart. This provided an extended range of thermal cycles in which a single product was produced and also extended the range in which a linear relationship was maintained between input target concentration and final amplified product concentration. These conditions are especially beneficial when using a nonspecific mode of detection, such as intercalating dyes that cannot distinguish between specific and nonspecific PCR products.

It is not difficult to design a nested PCR so that the initial phase of outer primer PCR remains in exponential amplification conditions. Using most commonly employed PCR protocols, the Taq DNA polymerase is almost always in great molar excess $(2.5 \mathrm{U} / 100 \mu \mathrm{l}$ equals
$8 \times 10^{10}$ molecules/100 $\left.\mu \mathrm{l}\right)$ throughout the initial $20-30$ cycles. Primers are also typically present in vast excess throughout almost all cycles of a regular PCR, but nested PCR uses a much lower, potentially limiting concentration of outer primers. Because the outer primers will generally be reduced to $5 \times 10^{-8} \mathrm{M}$ or less, it is important to avoid consuming a significant portion of the outer primers prior to addition of the inner primers.

A PCR will not generally depart from exponential phase until amplified product approaches at least one-tenth the outer primer concentration, or, in this example, at $\sim 1 \times 10^{-9} \mathrm{M}$ PCR product. It is easy to calculate the maximum number of outer primer PCR cycles that should be safely accommodated in the outer primer PCR. By rearranging equation 1 , the number of cycles, $\boldsymbol{n}$, that can be accommodated safely in the outer primer PCR phase can be calculated as

$$
n=\frac{\log \left[S_{n} / S_{(\max )}\right]}{\log \left(1+e_{1}\right)}
$$

where $S_{n}=$ maximum permitted product yield in outer-primer PCR (typically $1 / 10$ of outer primer concentration or $\sim 1 / 100$ the inner primer concentration), $S_{(\text {max })}=$ maximum target sequence concentration to be tested, and $e_{1}=$ outer primer PCR step efficiency if known or a value of 1 if unknown.

For example, employing $5 \times 10^{-8} \mathrm{M}$ of outer primers and starting with 1000 copies in $100 \mu \mathrm{l}\left(1.66 \times 10^{-17} \mathrm{M}\right)$, the maximum number of outer primer PCR cycles that could safely be accommodated with a step cycle efficiency of 1 would be 28 cycles. More cycles could safely be accommodated if the step cycle efficiency of the outer primer PCR was $<1$.

The value of $e_{1}$, the step cycle efficiency of the outer primer PCR, can be calculated easily from data taken entirely in the second stage of the nested PCR by rearranging equation 1 and solving for $e_{1}$. It is necessary to know $e_{2}$ (the step cycle efficiency of the inner primer PCR) and the amplification product yield from a known initial target concentration at a known thermal cycle number.

From data in taken from Figure $4 \mathrm{~A}$, the average step cycle efficiency of the inner primer PCR $\left(e_{2}\right)$ in the exponential phase was 0.80 . Knowing this, the average calculated value of the step cycle ef- 
ficiency for the outer primer PCR, $e_{1}$, was calculated from equation 1 to equal 0.52 .

Knowing the step cycle efficiency, the maximum amount of outer primer PCR product generated in the experiments of Figure 4, A and B, could be calculated. With 25,000 input copies, the yield of outer primer product was calculated to be $1.8 \times 10^{-9} \mathrm{M}$. This is only $9 \%$ of the level of supplied outer primers, within the range anticipated to support exponential phase amplification.

There are disadvantages to nested PCR. One is the obvious necessity to add the second set of primers. However, manual addition is not terribly inconvenient. The products from the outer primer PCR are very stable at $4^{\circ} \mathrm{C}$, so the addition of inner primers can be made at any time, which is convenient to the user. Another possible objection is physically opening the PCR reaction tubes, which increases the possibility of carryover contamination from previous reactions. However, this is not a great disadvantage, because nested primer PCR is an accepted technique for reducing the possibility of PCR product carryover; inner primer PCR products cannot be amplified in a subsequent reaction by outer primers.

One inherent limitation of nesting for quantitative applications is that at very large ranges of input copies (i.e., a millionfold or more) the permitted number of cycles in the initial, outer PCR will be limited by the maximum target concentration. Aside from this limitation, it is probably best on theoretical grounds to run about equal numbers of thermal cycles for both the inner and outer primer phases of the nested PCR. This should minimize amplification of nonspecific products from either set of primers.

Inner primer addition could also be automated, for example, by drop in/drop out PCR using outer and inner nested primers of greatly different melting temperatures. ${ }^{(7)}$ It remains to be demonstrated whether this type of nesting could produce as good quantitative results as a physical nesting procedure.

The major finding from this study is that it is not necessary that quantitative PCR be carried out with a single-step cycle efficiency. Two segments (or more, theoretically) with different step efficiencies are permissible. It is only important that all the initial phases (in which the PCR products are often at too low a concentration to detect) remain entirely in the exponential phase. These results also imply that other techniques to enhance PCR specificity, such as booster PCR, ${ }^{(8)}$ are probably also compatible with quantitation, even if they alter the step efficiency for a number of cycles in the amplification.

The mathematical model also suggests that quantitation with nested PCRs beyond the exponential phase should be possible using the Higuchi threshold model, ${ }^{(1)}$ as long as the initial, outer primer PCR phase was conducted entirely in the exponential phase. Further experimental work in this area is in progress.

\section{ACKNOWLEDGMENTS}

Technical discussions with John Atwood of Perkin-Elmer were essential in modeling the nested quantitative PCR.

\section{REFERENCES}

1. Higuchi, R., C. Fockler, G. Dollinger, and R. Watson. 1993. Kinetic PCR analysis: Real-time monitoring of DNA amplification reactions. Biotechnology 11: 10261030.

2. Wang, A.M. and D.F. Mark. 1990. Quantitative PCR. In PCR protocols (ed. M. Innis, D.H. Gelfand, J.J. Sninsky, and T.J. White), pp. 70-75. Academic Press, San Diego, CA.

3. Yourno, J. 1993. Direct polymerase chain reaction for detection of human immunodeficiency virus in blood spot residues on filter paper after elution of antibodies: An adjunct to serological surveys for estimating vertical transmission rates among human immunodeficiency virus antibody-positive newborns. J. Clin. Microbiol. 31: 1364-1367.

4. DiCesare, J., B. Grossman, E. Katz, E. Picozza, R. Ragusa, and T. Woudenberg. 1993. A high-sensitivity electrochemiluminescence-based detection system for automated PCR product quantitation. BioTechniques 15: 152-156.

5. LePecq, J.-B. and C. Paoletti. 1966. A new fluorometric method for RNA and DNA determination. Anal. Biochem. 17: 100107.

6. Holland, P.M., R.D. Abramson, R. Watson, and D.H. Gelfand. 1991. Detection of specific polymerase chain reaction product by utilizing the $5^{\prime} \rightarrow 3^{\prime}$ exonuclease activity of Termus aquaticus DNA polymerase. Proc. Natl. Acad. Sci. 88: 72767280 .

7. Erlich, H.A., D. Gelfand, and J.J. Sninsky, 1991. Recent advances in the polymerase chain reaction. Science 252: 1643-1651.
8. Phillips, D.J., J.M. Benson, J.M. Pruckler, and W.C. Hooper. 1992. PCR regimen for enhanced specificity yield of targeted genomic DNA sequencing: ras and p53. PCR Methods Applic. 2: 45-50.

Received December 29, 1993; accepted in revised form February 25, 1994. 


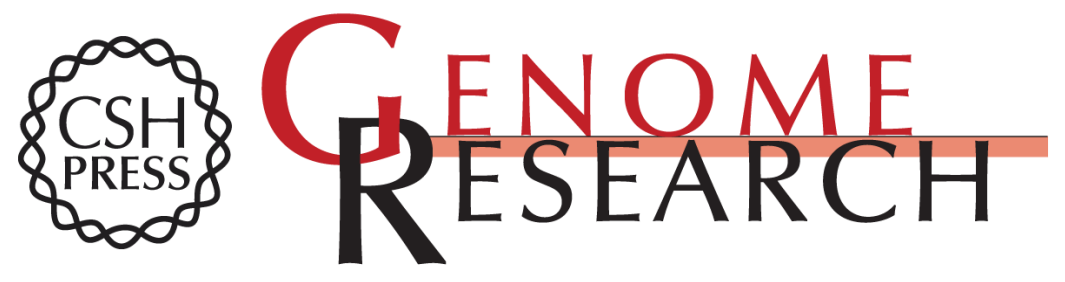

\section{Improved quantitative PCR using nested primers.}

L A Haff

Genome Res. 1994 3: 332-337

References This article cites 7 articles, 3 of which can be accessed free at: http://genome.cshlp.org/content/3/6/332.full.html\#ref-list-1

\section{License}

Email Alerting Receive free email alerts when new articles cite this article - sign up in the box at the Service top right corner of the article or click here.

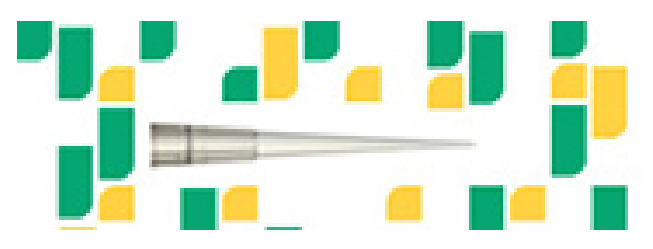

To subscribe to Genome Research go to: https://genome.cshlp.org/subscriptions 